\title{
A Participatory Action Research study on the impact of Peer Assisted Student Support (PASS) and Supplemental Instruction (SI) by international PhD students
}

\author{
Catherine Hayes \\ University of Sunderland, UK \\ John Anthony Fulton \\ University of Sunderland, UK
}

\section{Abstract}

Using a Participatory Action Research (PAR) approach, this evaluative research study gives an insight into the implementation of a pilot study of a newly implemented Peer Assisted Student Support (PASS) and Supplemental Instruction (SI) Programme. The focus of the study involved six postgraduate PhD students delivering a PASS/SI scheme to cohorts of MSc Public Health, MSc Nursing and MSc Psychosis and Complex Mental Health Interventions students, all undertaking their final dissertations. The study was used to illuminate the degree to which PASS and SI were perceived to impact on the overall student experience as part of a quality enhancement initiative. Findings of the study revealed that the programme had positively impacted on both PASS/SI leaders and participants of the scheme, who reported increased confidence and an increased sense of social inclusion and belonging to the institution respectively. Being facilitated by students who had experienced the same academic pathway was perceived to have widened networking opportunities and to have positively impacted on the capacity of the participants and leaders to build relationships and prepare skills of direct relevance to the requirements of an employer such as teamwork and initiative.

Keywords: Peer Assisted Student Support; Supplemental Instruction; postgraduate education; Participatory Action Research; student experience. 


\section{Contextual background to learning gain and PASS/SI}

Research from 2015 revealed there were several pre-existing definitions and conceptualisations of the term 'learning gain'. It was characterised in the report and operationally defined for the purposes of this small scale study, by the relative improvement in employability, knowledge and skills. It also has relevance to the temporality of learning gain, which can be measured between two distinct points in time (McGrath et al, 2015). However, learning gain is only one of many measures or metrics of the overall Higher Education student experience. This study provides a mechanism of contextualising and framing learning gain in postgraduate study in terms of the developmental opportunities available to students, which may directly impact on their relative employability and acquired transferable skill sets upon completion of their programmes generally and research specifically. This Rand Report (McGrath et al, 2015) also highlighted that learning gain ought not to be considered in terms of being a sole determinant of the quality of higher education that students experience and that 'quality of learning enhancement', (operationally defined for the purposes of this study as moving to the introduction of additional interventions to intentionally enhance the level of student experience), has to be regarded as relative to missions to improve for example transferable employability, the capacity to be creative or innovative or diverse enough to respond and adapt quickly to change (McGrath et al, 2015). The emphasis of this study is therefore to focus on the potential benefits gained from the implementation of a PASS/SI intervention from both postgraduate and international perspectives. One of the researchers (Catherine Hayes, $[\mathrm{CH}]$ ) undertook formal training with Lund University, Sweden (Certified SI-PASS Leader Training, April 2016). It is this specific recognised model of PASS/SI, which was implemented in practice in this study.

\section{Distinguishing features of learning gain for postgraduate students}

Postgraduate Master of Science student cohorts from the Health Team at the University of Sunderland have a shared project module which necessitates minimal attendance and provides one to one supervisory support. For many students this has historically been the most socially isolating element of their study in relation to available opportunities for social interaction and ongoing dialogue with their peers on either an academic or social level. The vast majority (96\%) of students are Nigerian and working with these particular 
students was acknowledged as an ideal opportunity to pilot a learning enhancement project specifically designed to support them a) in consolidating and sharing discourse about the academic work they had already undertaken, and b) enhanced levels of social interaction with their peer groups and others. This observation is not unique to the University of Sunderland and the evidence base is indicative of the impact of academic and social isolation and the contributory impact it has on student dissatisfaction, suboptimal achievement rates and ultimately withdrawal. From the relatively limited amount of literature available in the context of implementation of PASS/SI at postgraduate level, it is apparent that a clear infrastructure of support is necessary (Evans, 2015). This is something for exploration and illumination at a socio-cultural level if we are to challenge western ethnocentric approaches to educational support and delivery. Action research projects in this field have been slow to materialise since the initial identification of the need to counter isolation and improve academic and social interaction as long ago as a quarter of a century (Salmon, 2002; Conrad, Perry and Zuber-Skerritt, 1992). In common with previously reported studies it was evident that intervention in the form of a learning enhancement would need to be initiated by academic staff and advocated for implementation as part of learning gain for PhD students who had once been students on the programme themselves (Conrad and Zuber-Skerritt, 1995).

\section{Background literature and rationale for design of the pilot PASS/SI programme}

The purpose of the Case Study was to annotate how features of the pilot Peer Assisted Student Support (PASS) and Supplemental Instruction (SI) programme impacted on the student experience of both Doctoral (PhD) and Masters (MSc) degree students (Boud, Cohen and Sampson, 2014; Ali and Evans, 2013). The PASS and SI pilot intervention was designed with an awareness of the cultural and social links that Masters students already had with fellow Nigerian students, now undertaking PhD level study, who had previously experienced the same MSc programmes. It focused on the feedback that the PhD students had originally given on their experience of modules across the programme, where they had identified challenging areas of study in relation to the Applied Research Methods and Project Management module, a direct precursor to their final dissertation (Applied Practice Project module). This was positively regarded by students as they perceived that their opinions of the programme mattered and that measures were being actively taken to 
address helping them with challenging areas of study. It was also hoped that this would develop an identifiable culture of support for research students where capacity for social and academic networking between cohorts of students could be enhanced and facilitated as something that could potentially contribute to learning gain in the advent of the implementation of the proposed Teaching Excellence Framework (TEF). In terms of the potential for maximising learning gain, the concept of 'Learning Gain' was something that academic staff engaged in the execution of the pilot felt that PASS/SI could potentially actively contribute to in relation to the future implementation of the Teaching Excellence Framework (TEF).

\section{Postgraduate communities of practice}

By definition the use of community of practice is established and characterised by a group of people engaged in fundamental processes of collective learning. This is normally within the context of a specific domain and practical interventions are iteratively improved by the dynamics of human interaction (Wenger, 2010). In the context of the PASS/SI system which was made operational in the context of postgraduate provision, these domains are characterised by:

Domain: The domain within this study is postgraduate healthcare education. This educational context provided an ideal opportunity for reciprocity of MSc and PhD students. PhD students who voluntarily opted to engage in the development of a postgraduate PASS/SI system.

Community: The community are the PhD students who provide PASS/SI to MSc students in the context of a learning enhancement opportunity, which encourages developmental understanding of underpinning research methodologies and project management skills.

Practice: Whilst the defined community as a collective, belong to the healthcare education domain, the discipline of health has such a diversity of applied contexts that practice within each area can be very distinctive. The shared collective approach to learning about research in practice though, was the focus of the PASS/SI intervention. 


\section{Construction of PASS/SI training models}

A fundamental feature of any PASS/SI training model has to be the potential of the approach in enhancing the overall student experience in relation to the learning experiences of individual students and how this impacts on their level of motivation and commitment to achieve and maximise their potential. Seminal research has long highlighted the distinct link between the degree to which student motivation and overall attainment is impacted upon by learning environments and contexts within which students can develop higher order thinking skills and their capacity for autonomous, proactive engagement in specific learning goals. This is rooted in Self Determination Theory (Ryan and Deci, 2000) which posits that the extent to which any student is motivated to attain a personal academic goal is exponentially linked to their engagement in the student experience. The model of PASS/SI implemented in this study was designed to facilitate the development of student capacity for autonomous thinking and competence.

\section{PhD students as Peer Assisted Student Support facilitators}

The issue of facilitating learning via the use of peers is a longstanding issue in higher education, although little research exists on the development of integrated PASS/SI models in the context of postgraduate provision. From a discipline specific perspective the original interventions stemmed from the work of Vygotsky (1978) and Piaget (1976) and characterised social constructivist approaches to learning in an array of learning contexts.

The PhD students in this social context served to:

1. Enhance learning in the field of health research.

2. Focus attention on the need to be goal oriented, persistent, resilient and motivated to succeed in the context of their dissertation modules.

3. Provide exemplary input into an academic field in which they had already succeeded through their own motivation and commitment.

Gazula et al (2016) highlighted the value of reciprocity between givers and recipients of PASS/SI interventions and this was significant to this study since the PhD students had already experienced the same educational programme as the MSc students, having progressed into study for their higher degrees in previous academic years. This mutual shared experience meant that the PhD students were credible proponents of the need to 
remain motivated and committed in the dissertation module which is often perceived to be the most challenging aspect of the programme for most MSc students.

\section{Research methodology}

This study implemented a Participatory Action Research (PAR) approach as an overarching interpretivist methodological framework. It adopted qualitative methods (focus groups and semi-structured interviews) to evaluate the perceived experiences of students who engaged in the PASS/SI activities introduced as a pilot exercise for postgraduate MSc and PhD students. The approach offered a mechanism for the integration of concurrent and iterative conceptual planning, implementation and ongoing evaluation in the development of student learning enhancement.

A PAR was selected in relation to the potential evolution of new knowledge via critical reflection on action (McTaggart, Nixon and Kemmis, 2017). In the context of this study, this involved:

- Planning a specific additional change to the educational experience students have (i.e. the introduction of the PASS/SI intervention to postgraduate provision).

- Developing the PASS/SI system, implementing it in practice and then formally evaluating it.

- Integrating a mechanism of critical reflexivity and iterative and ongoing improvement to the PASS/SI intervention.

- Further integration of evaluative insight and re-development and implementation.

This PAR approach afforded the researchers an opportunity to identify a specific issue for address within the context of student learning experiences and to build this into the social co-construction of new knowledge in with these students. The aim of this was to translate collective emergent theoretical perspectives and findings from the study into innovative approaches into the comparatively new context of postgraduate PASS/SI provision. It can be posited that since knowledge is socially co-constructed in the context of a specific values system of postgraduate HE provision that this research approach encourages increasing levels of discourse around how students learn as well as what they learn in terms of disciplinary content. The approach also led to acknowledgement of the relevance of social interaction and served as a reminder that education is a social science, regardless of signature pedagogy and discipline. 


\section{Design and implementation of the PASS/SI pilot programme}

The pilot programme was designed with the broad aims of:

- Investigating whether recently published principles of PASS and SI could be effectively transferred and applied to this relatively specific context of provision in higher education.

- Consolidating the existing knowledge base that students had gained as a result of attending the module 'Applied Research Methods and Project Management'.

- Providing a social forum for students to engage with their peer group beyond the context of classroom based study as a means of reducing the sense of social isolation many previous students from the same stage of the programme had reported.

- Promoting the concept of socially inclusive collaborative experiential learning as a valuable adjunct to autonomous academic study.

\section{Curriculum design of the PASS / SI programme}

Prior to commencement of the project the researcher undertook formal supervisory training in Peer Assisted Student Support/Supplemental Instruction, which ensured that awareness of the difference between teaching and facilitation could be established (van der Meer, Spowart and Hart, 2013). The PhD students were then PASS/SI trained and equipped with the time and resources to undertake the pilot study. They were paid as Associate Tutors in the SI sessions as a means of making them accountable for their work with students in terms of learning content and delivery (Burgess, van Diggele and Mellis, 2015). They were not paid for engaging in the social activities. It was important that all students involved recognised the intrinsic potential worth the programme was perceived to have from the perspective of the academic staff involved and the students who had agreed to be PASS/SI facilitators during the pilot programme (Cusick et al, 2015). Overall, students from both cohorts regarded the programme as a positive experience and acknowledged this element of a quality enhancement initiative as something that added value to their learning journeys (McCartney, 2016; Carbone et al, 2015). An adaptation of this approach was made as a mechanism of providing a series of six learning consolidation sessions on: 
1. Philosophical Underpinnings of Approaches to Research Methods.

2. Referencing and Citation Techniques.

3. Undertaking Qualitative Data Analysis.

4. Undertaking Quantitative Data Analysis.

5. Constructing a Research Report/Dissertation.

6. Disseminating Research Workshop.

Alongside this the students were given the opportunity to attend a series of six writing retreat days, where the students could independently work on their own projects in the company of their peers, where they were free to socially engage, share concerns about their projects and be mentored by the six PhD students, who formed buddy groups. Finally a series of six free social events were organised in the form of beach walking, trips and social gatherings where students could integrate in social interaction and dialogue about their work, alongside having an opportunity to develop friendship groups which could be sustained around campus.

\section{Findings and evaluation of pilot PASS/SI project}

Two focus groups were undertaken to capture the group dynamics of PASS/SI Instruction (the PhD students, who became Focus Group A) and PASS/SI participation (the MSc students, who became Focus Group B). Focus groups were a means of capturing the dynamic interpersonal relationships within and between two distinct academic groups (MSc students and PhD students). It actively enabled their contribution to the co-construction of knowledge and streamlined discussions of topics and concepts that could be embedded back into academic curricula across the institution and lead to potential transferability between representative signature pedagogies. The captured dynamic between the MSc and PhD students as a consequence of the research approach adopted, led to the illumination of many agreed standpoints by students in their focus groups (Forsyth, 2014). Each focus group lasted 45 minutes and was conducted with a ratio of $1 \mathrm{PhD}$ student to $6 \mathrm{MSc}$ students, which reflected the construction of the PASS/SI model.

\section{Data analysis}

Braun and Clarke's (2006) six-phase approach to thematic analysis was adopted as a 
systematic, yet recursive, approach to inductive qualitative analysis. In accordance with recommendations of the process, data was not viewed in a linear fashion and ideas were extracted as they emerged during the process of interpretation (often after visiting and re-visiting particular focus group transcripts), and the researchers proceeded to the next phase where appropriate. The establishment of the most salient themes from the study were established using Quirkos (Quirkos Limited,Scotland), a commercial qualitative analysis software package tool, which enabled the overlap and predominance of key themes to be visually represented and prioritised for the discussion and findings of the research.

\section{Phase one}

This entailed familiarisation with the data set where the researchers immersed themselves in the data collected via extensive reading and re-reading of the transcribed information from the data collection. This was a process undertaken by two researchers where a consensus could be reached between those themes independently found to be most commonly occurring.

\section{Phase two}

Data was coded: this involved creating and identifying themes that came from analysis of the data sets. This subsequently guided analysis and provided a systematic approach at a semantic and conceptual level, which could be mapped against extant published literature. This was achieved by manually coding every data item and completed by the two researchers involved, collating every element together so that it could be independently checked for inclusion in the overall findings by both.

\section{Phase three}

This entailed exploring the data for the specific themes identified in Phase Two of the data analysis, defined in accordance with Braun and Clark (2006) as 'coherent and meaningful patterns in the data' of direct relevance to the research aim. If a theme emerged from more than $10 \%$ of respondents, it was deemed to be meaningful to the study. Its coherence was judged on the basis of non-ambiguous articulation of student perceptions. The authors attributed the degree of diversity in the questions asked to the fact that $100 \%$ of respondents contributed to at least four themes. 


\section{Phase four}

This stage involved reviewing the emergent themes. It provides a means of checking that these are relevant to the data extracts when they are taken in abstraction from the complete data set.

\section{Phase five}

Providing a definitive theme for each one that has emerged from the study entails defining the overall findings so that each can be individually examined.

\section{Phase six}

Analysing the themes relative to one another in terms of their rate of occurrence and writing up the findings in relation to this. This involved merging analytical narratives and examining this in relation to the existing published evidence base.

Following phase six of the data analysis, data were entered into Quirkos, which facilitated the authors in identifying the most salient themes from this phase of the research study. This also revealed distinct overlap between all themes and enabled us to present our findings without having to prioritise them in rank order. As such we present them as being equal but different, each necessitating individual consideration of relevance to proposed implementations of PASS/SI schemes in practice.

\section{Discussion and findings}

The six most salient emergent themes from the study were:

\section{Dialogic connection}

Students from both focus groups valued how PASS/SI had enabled them to extend their reach in entering active dialogue with each other about their work and its developmental progression. This was seen as an important means of ensuring that approaches and motivations to study remained energized, with a broader sense of connection socially and professionally to others in their cohorts.

\section{Student identity and belonging}


Students from both focus groups commented on the sense of belonging they felt both institutionally and to their respective academic cohorts as a result of the programme. The PhD students commented that, because this was paid employment they were engaging with, they had felt a sense of accountability for their contribution to learning enhancement, which they believed would be a valuable addition to their developing curricula vitae.

\section{Reciprocal reassurance and confidence building}

All students felt reassured to be able to meet other students from the same stage of study regularly, instead of seeing them in isolated social situations, where often their project work would not be the topic of conversation.

\section{Self-belief and aspiration}

The PhD students in particular said that undertaking a facilitator role in the PASS/SI system had enabled them to build confidence in working with others, which in turn enhanced their self-belief and focused their aspirational vision for working beyond the context of their doctoral studies (Williams and Reddy, 2016).

\section{Purposeful learning through facilitation rather than teaching}

MSc students as a collective, believed that the consolidation of learning across areas of the curriculum that were academically challenging, via further facilitation rather than more formalised teaching sessions, was a very beneficial approach (Choy, Delahaye and Saggers, 2015; Cook-Sather, Bovill and Felten, 2014).

\section{Cultural support and widening inclusion for others}

$96 \%$ of the students engaged in either PASS/SI as facilitators or recipients were Nigerian. The cultural ethos and shared experiences that were evident in this dynamic were positively received by all students, regardless of nationality, as a means of extending social circles with other students with whom they may never have had the opportunity to meet and engage with outside the classroom setting. This was warmly welcomed and many students commented that the contextual setting of the PASS/SI sessions had enabled them to form lasting friendships with others as a result (Bennett, O'Flynn and Kelly, 2015). 


\section{Conclusion}

This pilot study of PASS/SI delivered by PhD students to MSc students revealed the progressive development of an academic culture of reciprocity and support for student cohorts. This occurred both in relation to the learning development of the PhD students as PASS/SI facilitators and for the MSc student recipients, who felt that the intervention prevented feelings of social isolation during the period of their independent learning time. In particular, the integration of social activities across the scheme ensured a means of developing the social interrelationships between peer group learners at the institution. This particularly impacted upon student morale and motivation at what was perceived to be a challenging time. Students thought this challenge came from and was characterised by extensive preparation, critical thinking and the write-up of a lengthy dissertation. Being able to maintain and develop a dialogue of support during periods of time which could otherwise have been potentially isolating for MSc students, was reported to have made a significant difference to both. The PhD students felt that being able to conduct the PASS/SI system with a degree of functional autonomy within the institution had become an indicator of esteem. The process of facilitation further consolidated their own learning; they felt valued by the academic staff, whose work they were consolidating and reinforcing, and their own confidence in the context of their personal academic development grew. Their academic ability and their capacity to articulate key concepts were two areas highlighted.

If PASS/SI is to be implemented across the whole Faculty of Health Sciences and Wellbeing, rather than in a relatively small academic area such as Health, at the University, then several issues need to be addressed in relation to wider scaling of this project.

The PASS/SI intervention could potentially be applied to other disciplines and student groups in the institution as a mechanism of promoting the immediacy of the need for holistic academic integration, sense of belonging and student wellbeing, regardless of its impact on academic achievement. This has obvious and potentially positive wider implications for the holistic health and wellbeing of every student.

Pragmatically though, implementation of a PASS/SI scheme necessitates considerations, both strategically and operationally. These are identifiable across specific areas. Initially it would be necessary to establish a viable mechanism of being able to financially sustain 
the payment of facilitators. Potentially this could form part of an employer/employee relationship between the institution and the PhD students, tangibly acknowledging, rewarding and making them formally accountable for their work. Integrating mechanisms for students to express a preference for particular types of PASS/SI could also be a significant consideration. Linked to this would have to be the implication of the context and setting of informal learning for all students. relation to the contextual significance of PASS/SI this study provided evidence that the processes were perceived to provide an element of learning gain and this was evident through the demonstrably increased social cohesion, learning development of the PhD facilitators and the MSc students. In relation to this it is important to remember the aim of these sessions is to support learning in the context of a social and welcoming environment where inclusivity and belonging matter. Typical examples of this include whether the sessions are delivered at institutional or in home based settings, as depending on the context of delivery then communities of practice may differ in relation to their personal and professional impact.

Embedding the programme within and between different academic programmes, such as that seen between MSc and Doctoral level students might not always be potentially transferable in terms of the experience that students have gained. An example of this is the context of undergraduate provision, where more traditional approaches to PASS and SI, as predominantly separate entities may be better suited and aligned with both the need and the demand for provision of learning support. The recognition that the best students do not always make the best facilitators is also paramount to a successful scheme delivery. This has implications for processes of recruitment and retention of PASS/SI facilitators. The value placed upon those who are most reflective and reflexive in their approach to conveying experience and strategies for supporting others as they learn, is of extreme value and one which ought to be stressed at an operational level where students are being recruited to deliver PASS/SI schemes. Finally, reinforcing the need for students to consider the level of their commitment to becoming a PASS/SI facilitator requires clear academic leadership in practice. This is to enable the support of students who volunteer to deliver the scheme as they seek also to effectively balance commitment to their own doctoral studies. 
Whilst this is a relatively small study, the authors are hopeful that it might encourage other academic developers to consider the potential impact of trialling differing approaches to the delivery of PASS/SI schemes in their own academic practice.

\section{Ethical Approval}

Formal ethical approval for this study was obtained from the University of Sunderland Ethics Committee.

\section{References}

Ali, A. and Evans, P. (2013) 'Multi-resource peer assisted learning in postgraduate setting: a pilot study', Journal of the College of Physicians and Surgeons Pakistan, 23(4), pp. 251-256.

Bennett, D., O'Flynn, S., and Kelly, M. (2015) 'Peer assisted learning in the clinical setting: an activity systems analysis', Advances in Health Sciences Education, 20(3), pp. 595-610.

Boud, D., Cohen, R., and Sampson, J. (eds.) (2014) Peer learning in higher education: Learning from and with each other. Routledge.

Braun, V. and Clarke, V. (2006) 'Using thematic analysis in psychology', Qualitative Research in Psychology, 3(2), pp. 77-101.

Burgess, A., van Diggele, C., and Mellis, C. (2015) 'Students as facilitators in a teacher training program: motivation for leadership roles', Advances in medical education and practice, 6, pp. 615.

Carbone, A., Ross, B., Phelan, L., Lindsay, K., Drew, S., Stoney, S., and Cottman, C. (2015) 'Course evaluation matters: improving students' learning experiences with a peer-assisted teaching programme', Assessment \& Evaluation in Higher Education, 40(2), pp. 165-180. 
Choy, S., Delahaye, B. L., and Saggers, B. (2015) 'Developing learning cohorts for postgraduate research degrees', The Australian educational researcher, 42(1), pp. 19-34.

Conrad, L. and Zuber-Skerritt, O. (1995) 'Reaching more postgraduate students', in Conrad, L., and Phillips, L.A. (eds.) Reaching more students. Griffith University, Queensland: Griffith Institute for Higher Education, pp. 313-322.

Conrad, L., Perry, C., and Zuber-Skerritt, O. (1992) 'Alternatives to traditional postgraduate supervision in the social sciences', Starting research - supervision and training, Griffith University, Queensland: Griffith Institute for Higher Education, pp. 112-115.

Cook-Sather, A., Bovill, C., and Felten, P. (2014) Engaging students as partners in learning and teaching: A guide for faculty. John Wiley \& Sons.

Cusick, A., Camer, D., Stamenkovic, A., and Zaccagnini, M. (2015) Peer Assisted Study Sessions for research trainees. Journal of Peer Learning, 8(1), pp. 18-33.

Evans, H. (2015) 'International postgraduate students and peer learning', Journal of Pedagogic Development, 5(3).

Forsyth, K. D. (2014) 'Lessons learned in developing new postgraduate medical specialist training programs for Australia and New Zealand', The Medical Journal of Australia, 201(9), pp. 511-512.

Gazula, S., McKenna, L., Cooper, S., and Paliadelis, P. (2017) 'A systematic review of Reciprocal Peer Tutoring within tertiary health profession educational programs', Health Professions Education, 3(2), pp. 64-78.

Glass, C. R. and Westmont, C. M. (2014) 'Comparative effects of belongingness on the academic success and cross-cultural interactions of domestic and international students', International Journal of Intercultural Relations, 38, pp. 106-119. 
McCartney, M. (2016) 'Peer+ peer = increased learning', Science, 351(6268), pp. 38-39.

McGrath, C.H., Guerin, B., Harte, E., Frearson, M., and Manville, C., (2015) Learning gain in higher education. Santa Monica, CA: RAND Corporation US, pp 46-57.

McTaggart, R., Nixon, R., and Kemmis, S. (2017) 'Critical Participatory Action Research', in The Palgrave International Handbook of Action Research. Palgrave Macmillan US, pp. 21-35.

Piaget, J. (1976) 'Piaget's theory', in Piaget and his school. Springer Berlin Heidelberg, pp. 11-23.

Ryan, R. M. and Deci, E. L. (2000) 'Self-determination theory and the facilitation of intrinsic motivation, social development, and well-being', American Psychologist, 55(1), pp. 68.

Salmon, G. (2002) 'Mirror, mirror, on my screen -exploring online reflections', British Journal of Educational Technology, 33(4), pp. 379-391.

van der Meer, J., Spowart, L., and Hart, S. (2013), 'We need support too': Providing postgraduate peer support', The student engagement handbook: Practice in higher education. Emerald Group Publishing, pp. 313-330.

Vygotsky, L. S. (1978) 'Mind in society: The development of higher mental process', Cambridge; Harvard University Press, pp. 81-82

Wenger, E. (2010) 'Communities of practice and social learning systems: the career of a concept', in Blackmore, C. (ed.) Social learning systems and communities of practice. Springer, London, pp.179-198.

Williams, B. and Reddy, P. (2016) 'Does peer-assisted learning improve academic performance? A scoping review', Nurse Education Today, 42, pp. 23-29. 


\section{Author details}

Catherine Hayes is an Associate Professor of Health Professions Pedagogy at the University of Sunderland, a Visiting Professor of Higher Education Pedagogic Practice at the University of Cumbria, and a Visiting Professor of Higher Education at Liverpool Hope University.

John Fulton is an Associate Professor of Practice Based Research and Director of Postgraduate Research at the University of Sunderland. 